\title{
Critérios para condução do teste de tetrazólio em sementes de araucária
}

\author{
Bruna Ariane da Silva(1), José Luiz Nogueira(1), Elisa Serra Negra Vieira(2) e Maristela Panobianco(1)
}

\begin{abstract}
(1)Universidade Federal do Paraná, Setor de Ciências Agrárias, Departamento de Fitotecnia e Fitossanitarismo, Rua dos Funcionários, no 1.540, Bairro Juvevê, CEP 80035-050 Curitiba, PR, Brasil. E-mail: bruna_ariane2@hotmail.com, pdanogueira@yahoo.com.br, maristela@ufpr.br (2)Embrapa Florestas, Estrada da Ribeira, Km 11, Caixa Postal 319, Bairro Guaraituba, CEP 83411-000 Colombo, PR, Brasil. E-mail: elisa.vieira@embrapa.br
\end{abstract}

Resumo - O objetivo deste trabalho foi desenvolver critérios para condução do teste de tetrazólio em sementes de araucária (Araucaria angustifolia), com maior rapidez de execução e caracterização detalhada dos grupos de viabilidade. Inicialmente, foram conduzidos testes de germinação e de tetrazólio, de acordo as Regras para Análise de Sementes para Araucaria spp. Em seguida, avaliaram-se procedimentos mais práticos para condução do teste de tetrazólio, sem o pré-umedecimento das sementes e com a utilização de embriões excisados imersos diretamente na solução de tetrazólio; foram testadas três concentrações da solução $(0,075,0,2$ e $0,5 \%)$, três períodos de coloração (1, 2 e 4 horas) e duas temperaturas de coloração (30 e $\left.40^{\circ} \mathrm{C}\right)$. As médias obtidas por cada teste realizado foram comparadas pelo teste de Scott-Knott, a 1\% de probabilidade. O teste de tetrazólio pode ser empregado com eficiência e maior rapidez por meio da excisão dos embriões de araucária e da imersão direta na solução de tetrazólio, ao se utilizar as seguintes combinações de concentração/período/temperatura: $0,5 \% / 2$ horas $/ 30^{\circ} \mathrm{C}, 0,075 \% / 4$ horas $/ 40^{\circ} \mathrm{C}$ ou $0,5 \% / 2$ horas $/ 40^{\circ} \mathrm{C}$, as quais permitem a classificação das sementes em dois grupos distintos de viabilidade (viáveis e inviáveis).

Termos para indexação: Araucaria angustifolia, embrião excisado, grupo de viabilidade.

\section{Criteria for conduction of tetrazolium test on araucaria seeds}

\begin{abstract}
The objective of this work was to determine criteria for the conduction of tetrazolium test on araucaria (Araucaria angustifolia) seeds, with greater execution speed and detailed characterization of viability groups. Initially, germination and tetrazolium tests were conducted according to the Rules for Seed Testing for Araucaria spp. After that, more practical methods for carrying out the tetrazolium test were evaluated, without pre-wetting of the seeds and using excised embryos immersed directly in the tetrazolium solution; three concentrations of the solution $(0.075,0.2$, and $0.5 \%)$, three staining periods $(1,2$, and 4 hours), and two staining temperatures $\left(30\right.$ and $\left.40^{\circ} \mathrm{C}\right)$ were tested. The means obtained for each conducted test were compared by the Scott-Knott test, at $1 \%$ probability. The tetrazolium test may be effectively used through the excision of araucaria embryos and the direct immersion in the tetrazolium solution using the following combinations of concentration/period/temperature: $0.5 \% / 2$ hours $/ 30^{\circ} \mathrm{C}, 0.075 \% / 4$ hours $/ 40^{\circ} \mathrm{C}$, or $0.5 \% / 2$ hours $/ 40^{\circ} \mathrm{C}$, allowing the classification of the seeds into two different viability groups (viable and unviable).
\end{abstract}

Index terms: Araucaria angustifolia, excised embryos, viability groups.

\section{Introdução}

Aaraucária [Araucaria angustifolia (Bertol.) Kuntze], pertencente ao bioma Mata Atlântica (Watzlawick et al., 2011), é a única espécie do seu gênero com ocorrência natural no Brasil (Pires et al., 2013), especificamente nos estados do Paraná, de Santa Catarina e do Rio Grande do Sul. Da araucária, pode-se obter uma expressiva variedade de produtos e subprodutos (Soares \& Mota, 2004), e a comercialização de sua semente, o pinhão, apresenta-se como alternativa para a melhoria de renda de muitos produtores rurais.
Na literatura, vários estudos abordam a multiplicação assexuada da espécie, como a propagação por enxertia (Wendling et al., 2009; Zanette et al., 2011) e microenxertia (Anselmini \& Zanette, 2008). Entretanto, a produção de mudas de araucária é realizada principalmente via semente (Pires et al., 2013), o que ressalta a necessidade de métodos adequados para estimar a sua qualidade.

Nesse sentido, o teste de germinação tem sido rotineiramente empregado em tecnologia de sementes para avaliar a viabilidade destas; no caso de sementes de araucária, recomenda-se a primeira contagem 
aos 20 dias e a contagem final aos 31 dias (Brasil, 2013). Assim, o emprego de técnicas que determinem mais rapidamente a qualidade fisiológica da semente é importante, especialmente para espécies com comportamento recalcitrante (Oliveira et al., 2014) como a araucária (Caçola et al., 2006), as quais apresentam potencial de armazenamento relativamente curto.

O teste de tetrazólio pode ser utilizado como alternativa para estimar a viabilidade da semente em função da rapidez na obtenção de resultados. De acordo com as Regras para Análise de Sementes (Brasil, 2009), para Araucaria spp., o preparo da semente requer a remoção do pericarpo e o corte ou a punção da parte terminal e lateral da semente. No entanto, essa recomendação exige tempo considerável para execução. Além disso, como não se especifica a profundidade do corte ou da punção, ocorrem os seguintes problemas na coloração: se a camada do endosperma for muito espessa, o sal de tetrazólio não consegue penetrar e o tecido apresenta aspecto branco leitoso (morto); porém, se essa camada for muito fina, o embrião colorirá intensamente e apresentará aparência de tecido em deterioração.

Também indica-se um tempo de 18 horas para o pré-umedecimento em água, agravado por um longo período de coloração (18 a 25 horas), e uma concentração de $1 \%$ da solução de tetrazólio (Brasil, 2009). Quando esse procedimento é utilizado, as sementes adquirem coloração intensa, inclusive as viáveis, semelhante à de tecido deteriorado. Para sementes grandes, em geral, recomendam-se maiores concentrações da solução de tetrazólio para facilitar a coloração dos tecidos; contudo, a falta de especificidade da metodologia pode dificultar a interpretação dos resultados.

Assim, diversos autores sugerem a realização do teste de tetrazólio por meio da excisão e da análise do embrião, em substituição à semente inteira, como já feito em Acrocomia aculeata (Jacq.) Lodd. ex. Mart. (Ribeiro et al., 2010), Poecilanthe parviflora Benth. (Pinto et al., 2008) e Schizolobium parahyba (Vell.) Blake (Ferreira et al., 2007). Em araucária, Oliveira et al. (2014) recomendaram a retirada do embrião e a imersão na solução de tetrazólio; porém, antes, realizaram o pré-umedecimento das sementes em água por 18 horas, o que aumentou o tempo para conclusão do teste.
É necessário, portanto, aprimorar os critérios para condução do teste de tetrazólio em sementes de araucária, ao se testar os procedimentos que requeiram maior rapidez e facilidade de interpretação da viabilidade durante a análise. Há carência na literatura quanto à descrição detalhada e ilustrada de grupos de qualidade da semente, imprescindível para a reprodução do teste de tetrazólio.

O objetivo deste trabalho foi desenvolver critérios para condução do teste de tetrazólio em sementes de araucária (Araucaria angustifolia), com maior rapidez de execução e caracterização detalhada dos grupos de viabilidade.

\section{Material e Métodos}

As sementes (pinhões) utilizadas no experimento foram provenientes de pinhas de araucária, da variedade São José, coletadas na área de testes de procedências e progênies da espécie, localizada na Embrapa Florestas, no município de Colombo, PR.

As pinhas foram coletadas em março de 2014, com a utilização de podão e de lona de plástico para recolhimento dos frutos provenientes de árvores matrizes. A determinação do ponto de coleta foi baseada na mudança típica de coloração das pinhas, de verde para marrom. As sementes foram extraídas e beneficiadas manualmente, tendo-se eliminado as de tamanho pequeno localizadas nas extremidades (Nogueira \& Medeiros, 2007), as chochas e as falhas (escamas estéreis ou não fertilizadas).

Após o beneficiamento, as sementes foram encaminhadas, em embalagens de polipropileno de $22 \mu$, ao laboratório de análise de sementes; homogeneizadas e acondicionadas em embalagens do mesmo material; e mantidas em ambiente controlado, a $18^{\circ} \mathrm{C}$ e a $70 \%$ de umidade relativa do ar, até a realização das seguintes análises: determinação do teor de água das sementes, teste de germinação, testes de tetrazólio em semente e em embrião excisado.

Para a determinação do teor de água das sementes, utilizou-se o método de estufa a baixa temperatura de $101-105^{\circ} \mathrm{C}$, durante 17 horas, com duas repetições de três sementes cada uma; as sementes foram cortadas em três partes de dimensões semelhantes, com auxílio de guilhotina.

Já o teste de germinação foi conduzido com quatro repetições de 25 sementes cada uma; as sementes foram colocadas para germinar entre substrato de 
vermiculita saturada, no interior de caixas de plástico $(17,5 \times 13,2 \times 11,5 \mathrm{~cm})$ perfuradas. $\mathrm{O}$ condicionamento foi realizado em germinador do tipo Mangelsdorf, a $25^{\circ} \mathrm{C}$, por 31 dias (Brasil, 2013). Os resultados foram expressos em percentagem de plântulas normais.

Para o teste de tetrazólio em semente, foram utilizadas quatro repetições de 25 sementes pré-embebidas a $20^{\circ} \mathrm{C}$, por 18 horas, com posterior remoção e corte da parte terminal e lateral de cada uma delas. A coloração das sementes foi realizada com a imersão em solução com $1 \%$ de 2,3,5-trifenil tetrazólio, por 24 horas, a $30^{\circ} \mathrm{C}$, no escuro, em equipamento tipo BOD, de acordo com as Regras para Análise de Sementes (Brasil, 2009).

Para o teste de tetrazólio em embrião excisado, utilizaram-se quatro repetições de 25 embriões cada uma, e a excisão dos embriões foi realizada com auxílio de guilhotina, por meio de cortes nas laterais do tegumento e do endosperma até chegar próximo ao eixo embrionário; a partir deste ponto, a semente foi aberta manualmente para não danificar o embrião, que foi retirado (Figura 1). Os embriões foram avaliados individualmente, tendo-se realizado corte longitudinal no lado oposto à abertura dos cotilédones e verificado a ocorrência de danos nas faces interna e externa; quando observada a presença de injúrias, analisou-se a profundidade e a distância em relação ao eixo embrionário. Cada embrião excisado foi imerso diretamente em três concentrações de sal de tetrazólio $(0,075,0,2$ e $0,5 \%$ ), tendo-se testado duas temperaturas (30 e $\left.40^{\circ} \mathrm{C}\right)$ e três períodos de coloração (1,2 e 4 horas) no escuro; posteriormente, os embriões foram lavados em água corrente e analisados em microscópio estereoscópico. As concentrações e os períodos de coloração testados foram escolhidos após a realização de testes preliminares. Foram estabelecidos dois grupos de viabilidade da semente: Grupo I, viáveis; e Grupo II, inviáveis. Foram consideradas como áreas vitais: no eixo embrionário, a extremidade superior (plúmula), a extremidade lateral e a extremidade inferior (radícula); e, nos cotilédones, a proporção dos danos, tendo-se determinado, também, se estes afetavam mais da metade do tecido.

Para o procedimento estatístico, foi utilizado o delineamento inteiramente casualizado; as médias foram comparadas pelo teste de Scott-Knott, a 1\% de probabilidade; e os resultados foram expressos em percentagem. Utilizou-se o programa Assistat, versão 7.6 (Universidade Federal de Campina Grande, Campina Grande, PB, Brasil), para análise dos dados.

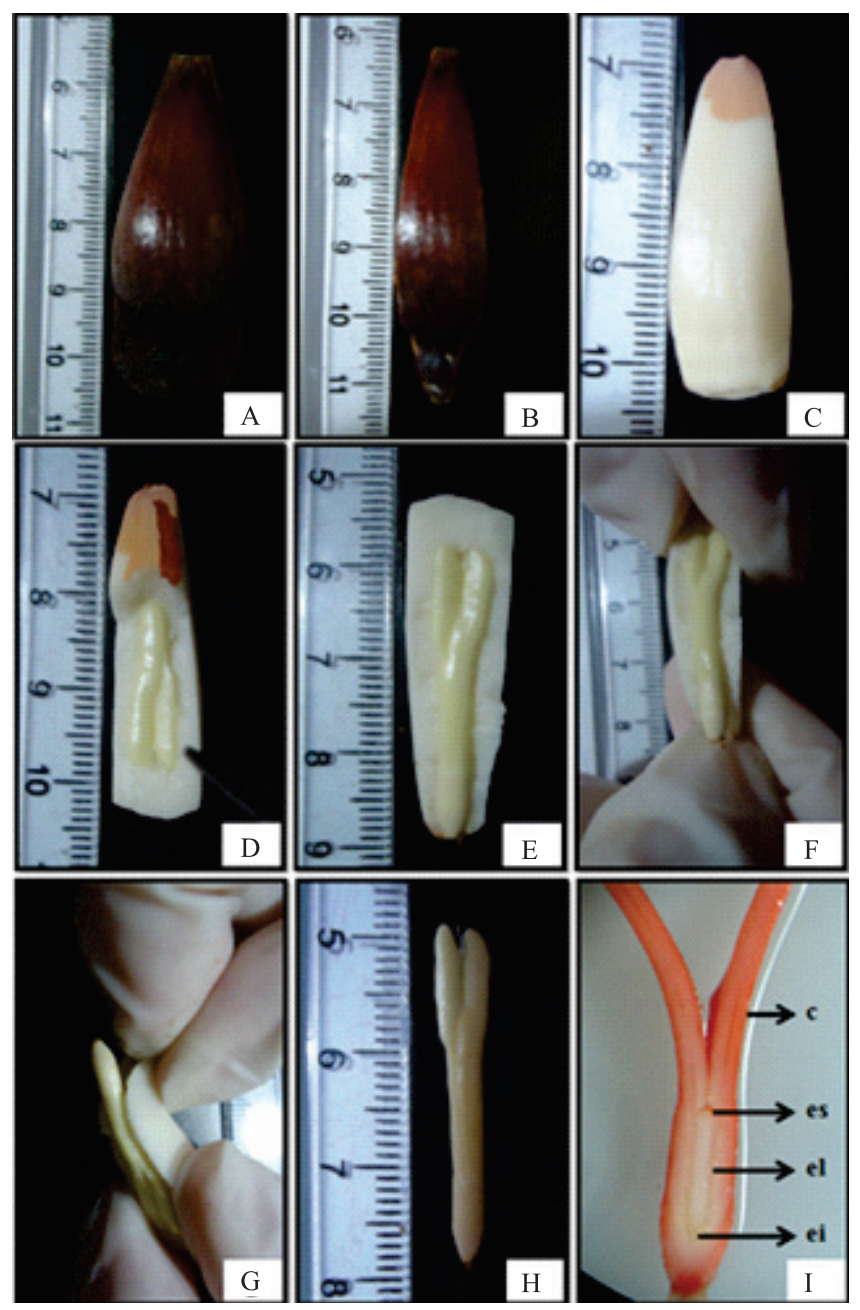

Figura 1. Excisão dos embriões de araucária (Araucaria angustifolia): A, vista externa da semente; B, sementes com partes laterais retiradas com guilhotina; $\mathrm{C}$, semente sem o pericarpo; $\mathrm{D}$, início da retirada manual do endosperma; $\mathrm{E}$, vista interna da semente; F, início da excisão do embrião; $G$, embrião parcialmente excisado; $\mathrm{H}$, embrião excisado; e I, estrutura do embrião excisado com corte longitudinal no lado oposto à abertura dos cotilédones, em que: c, cotilédones; es, extremidade superior do eixo embrionário; el, extremidade lateral do eixo embrionário; e ei, extremidade inferior do eixo embrionário. 


\section{Resultados e Discussão}

O teor de água das sementes de araucária, antes da realização dos testes, foi de $45,1 \%$, valor este superior ao nível crítico de umidade para a espécie (38\%), abaixo do qual ocorre a perda total da viabilidade da semente (Eira et al., 1994). Os grupos de viabilidade estabelecidos para sementes de araucária estão descritos na Figura 1. No Grupo I, de sementes viáveis, foram inseridas as sementes que apresentaram embriões de coloração vermelha carmim, uniforme, com tecido de aspecto normal e firme, sem danos significativos para a germinação e o estabelecimento de plântulas normais (Figura 2 A). Ainda nesse grupo, foram inseridos os
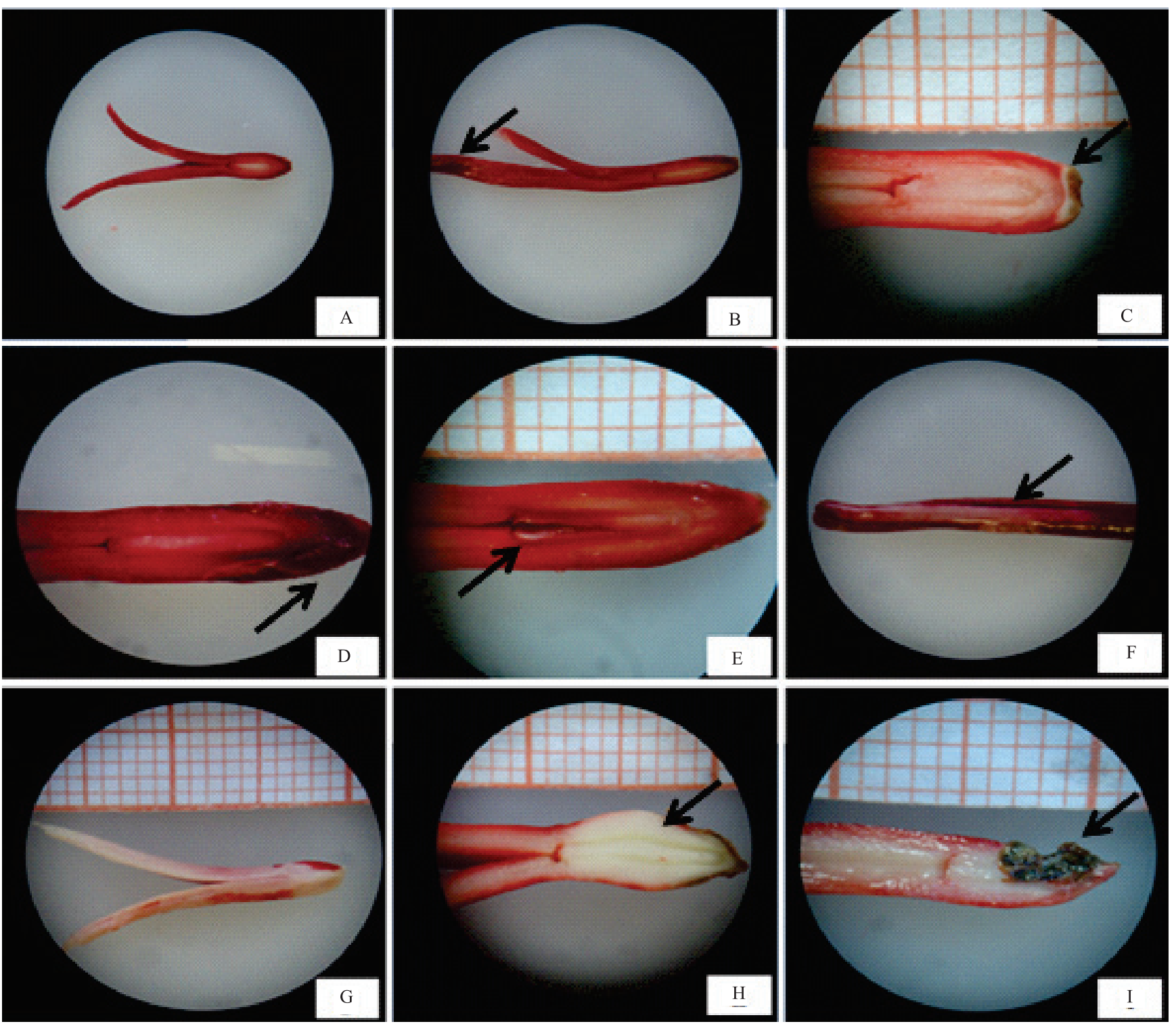

Figura 2. Descrição detalhada dos grupos de viabilidade de sementes de araucária (Araucaria angustifolia), no teste de tetrazólio. Grupo I, de sementes viáveis: A, embrião com coloração vermelha carmim, uniforme, de aspecto normal e firme; $\mathrm{B}$, embrião com menos da metade dos cotilédones com coloração vermelha intensa ou descoloridos; e C, embrião com dano superficial próximo à extremidade inferior do eixo embrionário (radícula), porém sem atingi-lo. Grupo II, de sementes inviáveis: D, embrião com coloração vermelha intensa, típica de tecido deteriorado, tendo atingido a extremidade inferior do eixo embrionário (radícula); E, embrião com dano na extremidade superior do eixo embrionário (plúmula); F, embrião com mais da metade dos cotilédones descoloridos; $\mathrm{G}$, embrião morto, quase totalmente descolorido; $\mathrm{H}$, embrião morto, com toda a extensão do eixo embrionário com coloração branca leitosa; e I, embrião morto, com tecido apodrecido. 
embriões que apresentaram menos da metade dos cotilédones descoloridos ou com coloração vermelha intensa (Figura 2 B), bem como os que apresentaram dano superficial próximo à extremidade inferior do eixo embrionário (radícula), sem, porém, atingi-lo (Figura $2 \mathrm{C}$ ), desde que as demais regiões apresentassem coloração uniforme e tecidos firmes. No Grupo II, de sementes inviáveis, enquadraram-se os embriões com tecido descolorido ou com coloração vermelha intensa na região da radícula (Figura $2 \mathrm{D}$ ) e na região da plúmula (Figura $2 \mathrm{E}$ ), e com mais da metade dos cotilédones descoloridos ou com coloração vermelha intensa (Figura 2 F). Nesse grupo, também foram inseridos os embriões mortos, que se encontravam quase totalmente descoloridos (Figura $2 \mathrm{G}$ ), com toda a extensão do eixo embrionário com coloração branca leitosa (Figura $2 \mathrm{H}$ ) ou com tecido apodrecido (Figura 2 I).

Os resultados dos testes de germinação e de tetrazólio estão descritos na Tabela 1. Constatou-se que a viabilidade obtida no teste de tetrazólio, conduzido com semente inteira e nas condições recomendadas pelas Regras para Análise de Sementes $\left(1 \% / 24\right.$ horas $\left./ 30^{\circ} \mathrm{C}\right)$, foi consideravelmente inferior à observada no teste de germinação. Ao se utilizar essa metodologia, verificouse a presença de poucas sementes viáveis (Figura $3 \mathrm{~A}$ ) e que a maior parte apresentava tecidos com coloração vermelha intensa (Figura $3 \mathrm{~B}$ e C) ou descoloridos

Tabela 1. Teste de germinação de sementes de araucária (Araucaria angustifolia) e teste de tetrazólio em semente inteira e em embrião excisado, com diferentes combinações de concentração da solução e períodos de coloração, a 30 e a $40^{\circ} \mathrm{C}^{(1)}$.

\begin{tabular}{lcc}
\hline Teste & \multicolumn{2}{c}{ Viabilidade (\%) } \\
\cline { 2 - 3 } & $30^{\circ} \mathrm{C}$ & $40^{\circ} \mathrm{C}$ \\
\hline Germinação & $86 \mathrm{a}$ & $86 \mathrm{a}$ \\
Tetrazólio/semente/1\%/24 horas & $14 \mathrm{~d}$ & $14 \mathrm{~d}$ \\
Tetrazólio/embrião excisado/0,075\%/1 hora & $35 \mathrm{c}$ & $51 \mathrm{c}$ \\
Tetrazólio/embrião excisado/0,075\%/2 horas & $86 \mathrm{a}$ & $83 \mathrm{a}$ \\
Tetrazólio/embrião excisado/0,075\%/4 horas & $76 \mathrm{~b}$ & $85 \mathrm{a}$ \\
Tetrazólio/embrião excisado/0,2\%/1 hora & $40 \mathrm{c}$ & $65 \mathrm{~b}$ \\
Tetrazólio/embrião excisado/0,2\%/2 horas & $76 \mathrm{~b}$ & $87 \mathrm{a}$ \\
Tetrazólio/embrião excisado/0,2\%/4 horas & $76 \mathrm{~b}$ & $80 \mathrm{a}$ \\
Tetrazólio/embrião excisado/0,5\%/1 hora & $45 \mathrm{c}$ & $69 \mathrm{~b}$ \\
Tetrazólio/embrião excisado/0,5\%/2 horas & $83 \mathrm{a}$ & $80 \mathrm{a}$ \\
Tetrazólio/embrião excisado/0,5\%/4 horas & $85 \mathrm{a}$ & $66 \mathrm{~b}$ \\
\hline CV (\%) & 10,0 & 9,7 \\
\hline (1)Médias seguidas de letras iguais, minúscula na coluna, não diferem pelo \\
teste de Scott-Knott, a 1\% de probabilidade.
\end{tabular}

(Figura 3 D). A coloração vermelha intensa, quando presente, indica a ocorrência de deterioração, enquanto a coloração branca leitosa caracteriza mortalidade. (Brasil, 2009).

Esse resultado pode ser atribuído à remoção do pericarpo e à retirada da parte lateral e terminal das sementes, como prescrito nas Regras para Análise de Sementes (Brasil, 2009). A remoção do tegumento possibilita maior uniformidade e rapidez durante a coloração (Gaspar-Oliveira et al., 2009); contudo, podem haver alterações em razão dos cortes e dos danos nas sementes durante o preparo (Cervi \& Mendonça, 2009), o que ocasiona equívocos na interpretação dos resultados. No caso da araucária, a falta de especificação da quantidade a ser removida do tegumento pode causar excesso ou falta de coloração, o que dificulta a análise.

Quanto ao teste de tetrazólio conduzido em embriões excisados, a 30 e $40^{\circ} \mathrm{C}$ (Tabela 1), tendo-se utilizado as metodologias do teste de germinação, as combinações que apresentaram médias estatisticamente semelhantes
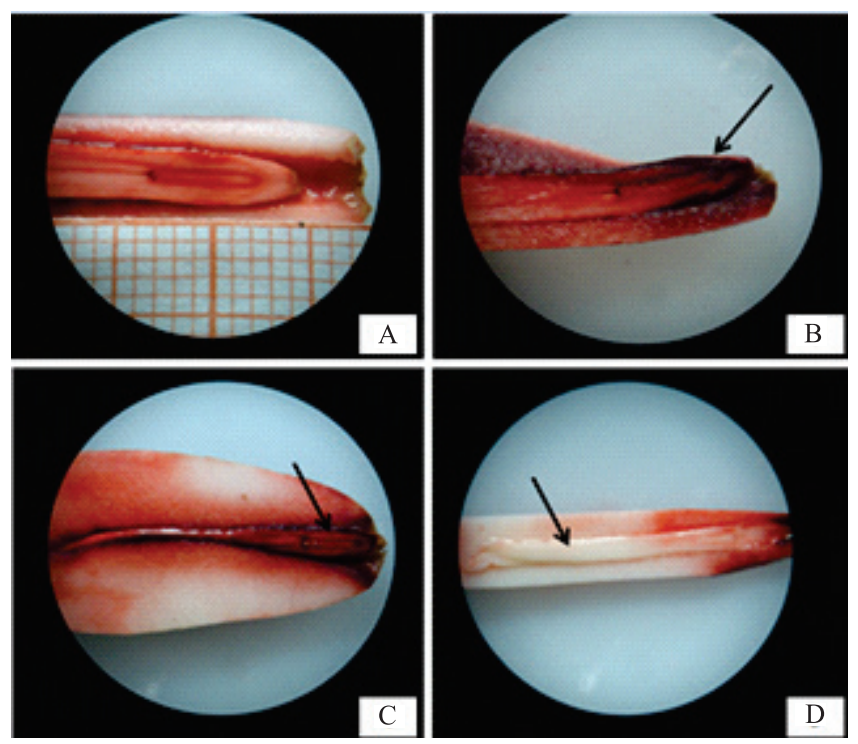

Figura 3. Aspecto das sementes de araucária (Araucaria angustifolia) após o teste de tetrazólio, realizado de acordo com as Regras para Análise de Sementes (Brasil, 2009): A, semente com coloração vermelha carmim, uniforme; $\mathrm{B}$, semente com coloração vermelha intensa na região da radícula; $\mathrm{C}$, semente com coloração vermelha intensa ao longo do eixo embrionário e dos cotilédones; e $\mathrm{D}$, semente descolorida. 
foram: $\quad 0,075 \% / 2 \quad$ horas $/ 30^{\circ} \mathrm{C} \quad$ (Figura 4 A); $0,5 \% / 2$ horas $/ 30^{\circ} \mathrm{C}$ (Figura $4 \mathrm{~B}$ ); $0,5 \% / 4$ horas $/ 30^{\circ} \mathrm{C}$ (Figura $4 \mathrm{C}$ ); $0,075 \% / 2$ horas $/ 40^{\circ} \mathrm{C}$ (Figura $4 \mathrm{D}$ ); $0,075 \% / 4$ horas $/ 40^{\circ} \mathrm{C}$ (Figura $4 \mathrm{E}$ ); $0,2 \% / 2$ horas $/ 40^{\circ} \mathrm{C}$ (Figura $4 \mathrm{~F}$ ); $0,2 \% / 4$ horas $/ 40^{\circ} \mathrm{C}$ (Figura $4 \mathrm{G}$ ); e $0,5 \% / 2$ horas $/ 40^{\circ} \mathrm{C}$ (Figura $4 \mathrm{H}$ ).

Dos três tratamentos a $30^{\circ} \mathrm{C}$ que apresentaram resultadossemelhantesaosobtidosnotestedegerminação (Tabela 1), a combinação de $0,5 \% / 2$ horas $/ 30^{\circ} \mathrm{C}$ foi a que possibilitou a melhor visualização das estruturas e dos danos (Figura $4 \mathrm{~B}$ ). Porém, nos tratamentos a $40^{\circ} \mathrm{C}$ (Tabela 1), as combinações de $0,075 \% / 4$ horas $/ 40^{\circ} \mathrm{C}$ e $0,5 \% / 2$ horas $/ 40^{\circ} \mathrm{C}$ foram eficientes na identificação da estrutura dos embriões (Figura 4 E e 4 H). Para a redução de custo, menores concentrações de solução de tetrazólio são indicadas (Dias \& Alves, 2008), as quais também podem possibilitar eficiente visualização e identificação dos tipos de injúrias (França Neto et al., 1998).

A metodologia do teste de tetrazólio em embriões também foi avaliada em outras espécies florestais, como angico [Anadenanthera peregrina (L.) Speg.], para o qual é recomendada a concentração de $0,1 \%$, a $30^{\circ} \mathrm{C}$, por 24 horas (Pinho et al., 2011), e ipê-branco [Tabebuia roseoalba (Ridl.) Sandwith], para o qual é indicada a concentração de $0,5 \%$, a $36^{\circ} \mathrm{C}$, durante 24 horas (Abbade \& Takaki, 2014). No caso da araucária, Oliveira et al. (2014) obtiveram melhores resultados com as concentrações de 0,1 ou $0,5 \%$ por 1 hora, a $25^{\circ} \mathrm{C}$, porém incluíram um período de pré-umedecimento das sementes por 18 horas antes da extração dos embriões, o que acarretou expressivo aumento do tempo de análise.

Dessa forma, as combinações que possibilitaram a melhor visualização das estruturas e dos danos nos
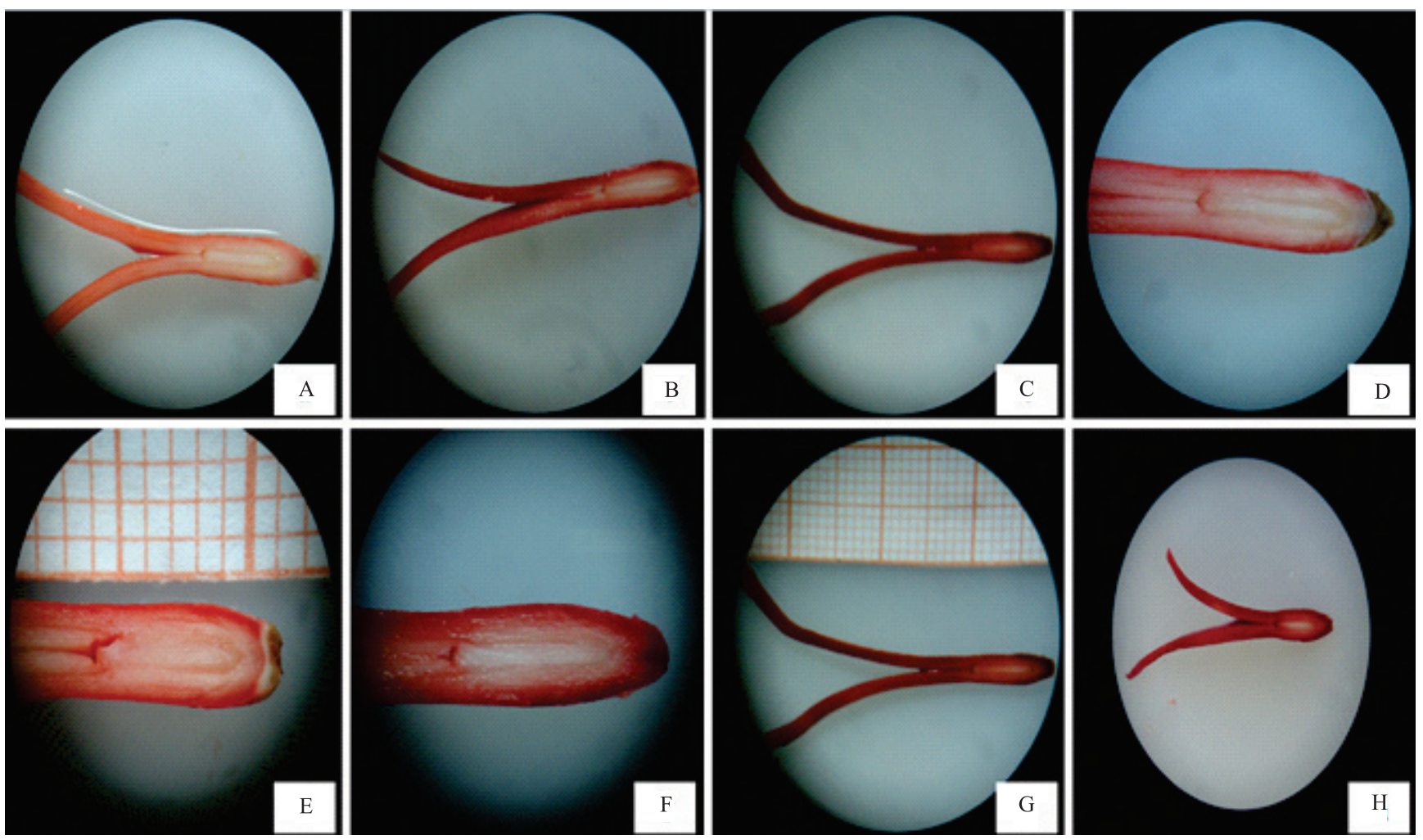

Figura 4. Teste de tetrazólio conduzido com embriões excisados de araucária (Araucaria angustifólia), tendo-se utilizado as metodologias do teste de germinação, com as seguintes combinações de concentrações da solução/períodos/temperatura: A, $0,075 \% / 2$ horas $/ 30^{\circ} \mathrm{C} ; \mathrm{B}, 0,5 \% / 2$ horas $/ 30^{\circ} \mathrm{C} ; \mathrm{C}, 0,5 \% / 4$ horas $/ 30^{\circ} \mathrm{C} ; \mathrm{D}, 0,075 \% / 2$ horas $/ 40^{\circ} \mathrm{C} ; \mathrm{E}, 0,075 \% / 4$ horas $/ 40^{\circ} \mathrm{C} ; \mathrm{F}$, $0,2 \% / 2$ horas $/ 40^{\circ} \mathrm{C} ; \mathrm{G}, 0,2 \% / 4$ horas $/ 40^{\circ} \mathrm{C}$; e $\mathrm{H}, 0,5 \% / 2$ horas $/ 40^{\circ} \mathrm{C}$. 
embriões de araucária foram: $0,5 \% / 2$ horas $30^{\circ} \mathrm{C}$, $0,075 \% / 4$ horas $/ 40^{\circ} \mathrm{C}$ e $0,5 \% / 2$ horas $/ 40^{\circ} \mathrm{C}$. Para a avaliação da viabilidade das sementes, a utilização da concentração de $0,075 \%$ traz benefícios para a análise de rotina, em razão do menor custo; no entanto, para a redução de tempo, a utilização dos demais tratamentos é mais vantajosa. Além disso, o presente trabalho proporciona um ganho no período para obtenção de resultados, em todos os tratamentos, uma vez que não foi necessário realizar o pré-umedecimento das sementes por 18 horas.

\section{Conclusão}

O teste de tetrazólio apresenta eficiência e maior rapidez quando realizado por meio da imersão direta de embriões excisados em solução de tetrazólio, ao se utilizar as seguintes combinações de concentração/período/temperatura: $0,5 \% / 2$ horas $/ 30^{\circ} \mathrm{C}$, $0,075 \% / 4$ horas $/ 40^{\circ} \mathrm{C}$ ou $0,5 \% / 2$ horas $/ 40^{\circ} \mathrm{C}$, as quais permitem a classificação das sementes em dois grupos distintos de viabilidade (viáveis e inviáveis).

\section{Agradecimentos}

À Coordenação de Aperfeiçoamento de Pessoal de Nível Superior (Capes), pela concessão de bolsa.

\section{Referências}

ABBADE, L.C.; TAKAKI, M. Teste de tetrazólio para avaliação da qualidade de sementes de Tabebuia roseoalba (Ridl.) Sandwith - Bignoniaceae, submetidas ao armazenamento. Revista Árvore, v.38, p.233-240, 2014. DOI: 10.1590/S0100-67622014000200003.

ANSELMINI, J.I.;ZANETTE, F. Microenxertia e sua caracterização morfológica em Araucaria angustifolia. Ciência Rural, v.38, p.967-973, 2008. DOI: 10.1590/S0103-84782008000400010.

BRASIL. Ministério da Agricultura, Pecuária e Abastecimento. Instruções para análise de sementes de espécies florestais. Brasília: Ministério da Agricultura, Pecuária e Abastecimento, SDA, 2013. 97p. Disponível em: < http://www.agricultura.gov.br/ arq_editor/file/Laboratorio/Sementes/FLORESTAL_documento_ pdf $>$. Acesso em: 20 fev. 2014.

BRASIL. Ministério da Agricultura, Pecuária e Abastecimento. Regras para análise de sementes. Brasília: MAPA,SDA, 2009. 395p.

CAÇOLA, A.V.; AMARANTE, C.V.T. do; FLEIG, F.D.; MOTA, C.S. Qualidade fisiológica de sementes de Araucaria angustifolia (Bertol.) Kuntze submetidas a diferentes condições de armazenamento e a escarificação. Ciência Florestal, v.16, p.391-398, 2006.
CERVI, F.; MENDONÇA, E.A.F. Adequação do teste de tetrazólio para sementes de algodoeiro. Revista Brasileira de Sementes, v.31, p.177-186, 2009. DOI: 10.1590/S0101-31222009000100020.

DIAS, M.C.L. de L.; ALVES, S.J. Avaliação da viabilidade de sementes de Panicum maximum Jacq pelo teste de tetrazólio. Revista Brasileira de Sementes, v.30, p.152-158, 2008. DOI: 10.1590/S0101-31222008000300020.

EIRA, M.T.S.; SALOMÃO, A.N.; CUNHA, R. da; CARRARA, D.K.; MELLO, C.M.C. Efeito do teor de água sobre a germinação de sementes de Araucaria angustifolia (Bert.) O. Ktze. Araucariaceae. Revista Brasileira de Sementes, v.16, p.71-75, 1994. DOI: 10.17801/0101-3122/rbs.v16n1p71-75.

FERREIRA, R.A.; OLIVEIRA, L.M. de; TONETTI, O.A.O.; DAVIDE, A.C. Comparação da viabilidade de sementes de Schizolobium parahyba (Vell.) Blake - leguminosae caesalpinioideae, pelos testes de germinação e tetrazólio. Revista Brasileira de Sementes, v.29, p.83-89, 2007. DOI: 10.1590/ S0101-31222007000300011.

FRANÇA NETO, J.B.; KRZYZANOWSKI, F.C.; COSTA, N.P. da. O teste de tetrazólio em sementes de soja. Londrina: EMBRAPA-CNPSO, 1998. 72p. (EMBRAPA-CNPSO Documentos, 116).

GASPAR-OLIVEIRA, C.M.; MARTINS, C.C.; NAKAGAWA, J. Método de preparo das sementes de mamoneira (Ricinus communis L.) para o teste de tetrazólio. Revista Brasileira de Sementes, v.31, p.160-167, 2009. DOI: 10.1590/ S0101-31222009000100018.

NOGUEIRA, A.C.; MEDEIROS, A.C. de S. Coleta de sementes florestais nativas. Colombo: Embrapa Florestas, 2007. 11p. (Embrapa Florestas. Circular técnica, 144). Disponível em: < http://ainfo.cnptia.embrapa.br/digital/bitstream/ CNPF-2009-09/42601/1/Circular144.pdf $>$. Acesso em: 20 nov. 2014

OLIVEIRA, L.M. de; GOMES, J.P.; SOUZA, G.K.; NICOLETTI, M.F.; LIZ, T.O. de; PIKART, T.G. Metodologia alternativa para o teste de tetrazólio em sementes de Araucaria angustifolia (Bertol.) Kuntze. Floresta e Ambiente, v.21, p.468-474, 2014. DOI: 10.1590/2179-8087.064413.

PINHO, D.S.; BORGES, E.E. de L.; CARVALHO, A.P.V.; CORTE, V.B. Adequação da metodologia do teste de tetrazólio para avaliação da viabilidade de sementes de angico. Pesquisa Florestal Brasileira, v.31, p.269-272, 2011. DOI: 10.4336/2011. pfb.31.67.269.

PINTO, T.L.F.; BRANCALION, P.H.S.; NOVEMBRE, A.D.L.C.; CICERO, S.M. Avaliação da viabilidade de sementes de coração-de-negro (Poecilanthe parviflora Benth. - Fabaceae-Faboideae) pelo teste de tetrazólio. Revista Brasileira de Sementes, v.30, p.208-214, 2008. DOI: 10.1590/ S0101-31222008000100026.

PIRES, P.P.; WENDLING, I.; BRONDANI, G. Ácido indolbutírico e ortotropismo na miniestaquia de Araucaria angustifolia Revista Árvore, v.37, p.393-399, 2013. DOI: 10.1590/ S0100-67622013000300002.

RIBEIRO, L.M.; GARCIA, Q.S.; OLIVEIRA, D.M.T.; NEVES, S.C. Critérios para o teste de tetrazólio na estimativa do potencial 
germinativo em macaúba. Pesquisa Agropecuária Brasileira, v.45, p.361-368, 2010. DOI: 10.1590/S0100-204X2010000400003.

SOARES, T.S.; MOTA, J.H. Araucária - o pinheiro brasileiro. Revista Científica Eletrônica de Engenharia Florestal, v.3, p.1-8, 2004.

WATZLAWICK, L.F.; EBLING, A.A.; RODRIGUES, A.L.; VERES, Q.J.I.; LIMA, A.M. de. Variação nos teores de carbono orgânico em espécies arbóreas da Floresta Ombrófila Mista. Floresta e Ambiente, v.18, p.248-258, 2011. DOI: 10.4322/ floram.2011.045.
WENDLING, I.; DUTRA, L.F.; HOFFMANN, H.A.; BETTIO, G.; HANSEL, F. Indução de brotações epicórmicas ortotrópicas para a propagação vegetativa de árvores adultas de Araucaria angustifolia. Agronomía Costarricense, v.33, p.309-319, 2009 .

ZANETTE, F.; OLIVEIRA, L. da S.; BIASI, L.A. Grafting of Araucaria angustifolia (Bertol.) Kuntze through the four seasons of the year. Revista Brasileira de Fruticultura, v.33, p.1364-1370, 2011. DOI: $10.1590 / \mathrm{S} 0100-29452011000400040$

Recebido em 7 de maio de 2015 e aprovado em 13 de novembro de 2015 